\title{
BMC Biophysics reviewer acknowledgement 2014
}

Catherine J Potenski

\section{Contributing reviewers}

The editors of BMC Biophysics would like to thank all our reviewers who have contributed to the journal in Volume 7 (2014).

$\begin{array}{lll}\text { Nathan Baker } & \text { Themis Lazaridis } & \text { Sanbo Qin } \\ \text { USA } & \text { USA } & \text { USA } \\ \text { Andrew Burnett } & \text { Timothy Lezon } & \text { Arvind Ramanathan } \\ \text { UK } & \text { USA } & \text { USA } \\ \text { Miguel Castanho } & \text { Ray Luo } & \text { Markus Sauer } \\ \text { Portugal } & \text { USA } & \text { Germany } \\ \text { Martin Depken } & \text { Christopher Mathews } & \text { Michael Schlierf } \\ \text { Netherlands } & \text { USA } & \text { Germany } \\ \text { Markus Dittrich } & \text { Andrew J Mccammon } & \text { Sundar Raman Subramanian } \\ \text { USA } & \text { USA } & \text { USA } \\ \text { Pemra Doruker } & \text { Ralf Metzler } & \text { Attila Szabo } \\ \text { Turkey } & \text { Germany } & \text { USA } \\ \text { Robert Falconer } & \text { Christine Milcarek } & \text { Vladimir Turzhitsky } \\ \text { UK } & \text { USA } & \text { USA } \\ \text { Dmitri Fedorov } & \text { James Milner-White } & \text { Katarzyna Tych } \\ \text { Japan } & \text { UK } & \text { UK } \\ \text { Michael Feig } & \text { Dariush Mohammadyani } & \text { Maximilian Ulbrich } \\ \text { USA } & \text { USA } & \text { Germany } \\ \text { Susan M Gasser } & \text { Subhodeep Moitra } & \text { Hongyun Wang } \\ \text { Switzerland } & \text { USA } & \text { USA } \\ \text { Gernot Guigas } & \text { Paul Moss } & \text { Wei Yang } \\ \text { Germany } & \text { UK } & \text { USA } \\ \text { Gary Huber } & \text { Edward Parrott } & \\ \text { USA } & \text { UK } & \end{array}$

Correspondence: catherine.potenski@biomedcentral.com

BioMed Central, 233 Spring Street, New York 10013-1578, NY, USA 